\title{
Synthesis and catalytic applications of metal-organic frameworks: a review on recent literature
}

\author{
V. R. Remya ${ }^{1} \cdot$ Manju Kurian ${ }^{1}$
}

Received: 23 July 2018 / Accepted: 26 November 2018 / Published online: 5 December 2018

(c) The Author(s) 2018

\begin{abstract}
Metal-organic frameworks (MOFs) are an emerging class of porous materials created by the assembly of inorganic connectors and organic linkers. They have potential applications in fields such as gas storage as well as separation, sensing, catalysis, and drug delivery due to its properties such as flexibility, porosity, high surface area and functionality. Among the various synthetic approaches for the preparation of MOFs, solvothermal and microwave-assisted methods are of particular importance, and hence have been used frequently. They have been recently used as heterogeneous catalysts in Friedel-Crafts reactions, condensations reactions, oxidations, coupling reactions, etc. However, owing to the low thermal stability and moisture sensitivity, their catalytic applications are limited. This short review covers recent developments in the synthetic methods employed for the preparation of MOFs as well as their catalytic applications.
\end{abstract}

Keywords Metal-organic framework $\cdot$ Synthesis techniques $\cdot$ Stability $\cdot$ Heterogeneous catalyst

Abbreviations
$\begin{array}{ll}\mathrm{H}_{2} 2,3-\text { pydc } & \text { Pyridine-2,3-dicarboxylic acid } \\ \text { bpp } & \text { 1,3-Bis(4-pyridyl)propane } \\ \mathrm{H}_{2} \text { bpabdc } & \text { 2,5-Bis(phenylamino)-1,4-benzenedicarbox- } \\ & \text { ylic acid } \\ \mathrm{H}_{2} \text { tdc } & \text { Thiophene-2,5-dicarboxylic acid } \\ \mathrm{H}_{4} \text { abtc } & 3,3^{\prime}, 5,5^{\prime} \text {-Azobenzene-tetracarboxylic acid } \\ \text { ad } & \text { Adenine } \\ \mathrm{H}_{3} \text { btc } & \text { 1,3,5-Benzene tricarboxylic acid } \\ \mathrm{H}_{2} \text { bdc } & 1,4-\text {-Benzenedicarboxylic acid } \\ \text { pdc } & \text { 2,6-Pyridinedicarboxylate } \\ \text { DMI } & 1,3 \text {-Dimethyl-2-imidazolidinone } \\ \text { DMA } & N, N^{\prime} \text {-Dimethylacetamide } \\ \text { DMF } & N, N^{\prime} \text {-Dimethyl formamide } \\ \text { THF } & \text { Tetrahydrofuran } \\ \text { TBHP } & \text { tert-Butyl hydroperoxide } \\ \text { DMI } & 1,3 \text {-Dimethy-2-imidazolidinone }\end{array}$

Manju Kurian

mk@macollege.in

1 Department of Chemistry, Mar Athanasius College, Kothamangalam 686666, India

\section{Introduction}

Metal-organic frameworks (MOFs) are a novel class of porous materials recently developed by material scientists. They are crystalline, organic-inorganic hybrid compounds in which metal ions and organic multidentate ligands are linked together by coordinate bonds. MOFs exhibit high surface areas with tunable functionality and pore size, enhanced activity than base metal oxides, shape/size selectivity. As a result, they have been used as hosts for a variety of guest molecules [1-3]. They also find applications in adsorption, catalysis, magnetism, sensing and drug delivery [4-6]. The physical properties of MOFs such as magnetic susceptibility, conductivity and optical characteristics are decided by the nature of metal-organic framework as a solid [7].

Over the last two decades, a lot of research work has been done on MOFs. Transition metals, alkaline earth metals, p-block elements, actinides and even mix metals are used for the synthesis of MOFs. N-containing aromatics or multivalent aromatic carboxylic acids are commonly used organic linkers in MOFs. Based on the size of inorganic building units and ligands as well as framework connectivity, pores and open channels with sizes ranging from angstroms to nanometers can be present [7]. Traditionally used porous materials such as zeolites possess small pore size and silicate materials have too large large. MOFs bridge the gap between these two classes of porous materials. MOFs with 
pore sizes ranging from ultramicropores to mesopores have been reported in literature. However, compared to oxides, MOFs show lower chemical, thermal, and hydrothermal stability [8]. This short review attempts to consolidate the recent developments in the field of MOF synthesis and their catalytic applications.

\section{Synthesis of MOFs}

Many methods are available for the synthesis of MOFs. Majority of these occur in liquid phase, where the metal salt and ligand solutions are prepared separately and mixed together or solvent is added to a mixture of solid salt and ligand. Selection of solvent is crucial for the synthesis of MOFs with better characteristics and usually depends on different features like redox potential, reactivity, stability constant, solubility, etc.

\section{Slow evaporation method}

In this method, the precursors are dissolved in a solvent or a mixture of solvents. Slow evaporation of the solvent takes place at a particular temperature usually at inert atmosphere. It is a conventional method for the preparation of MOF, without any external energy supply. Solubility of the reagents is a major problem while preparing MOF by this method. Therefore, mixture of solvents can be used to increase the solubility. Though the technique can be employed at room temperature, it is a time-consuming process. Murinzi et al. [9] developed a new supramolecular MOF with cobalt as metal ion and 2, 6-pyridinedicarboxylic acid as linker by slow evaporation method. The synthesized cobalt MOF was found to be effective for detection of L-cysteine. Wang et al. [10] prepared three new metal-organic frameworks, $\left[\mathrm{Cu}(2,3-\right.$ pydc)(bpp) $] \cdot 2.5 \mathrm{H}_{2} \mathrm{O},\left[\mathrm{Zn}(2,3-\right.$ pydc) (bpp) $] \cdot 2.5 \mathrm{H}_{2} \mathrm{O}$ and $\left[\mathrm{Cd}(2,3-\right.$ pydc $\left.)(\mathrm{bpp})\left(\mathrm{H}_{2} \mathrm{O}\right)\right] \cdot 3 \mathrm{H}_{2} \mathrm{O}$ at room temperature. The latter two complexes showed intense fluorescent emissions in photoluminiscent study.

\section{Solvothermal synthesis}

Solvothermal method is the most recurrently used method for the preparation of MOFs as it provides a variety of morphologies. In this method, the reaction occurs between the metal salt and the organic ligand in organic solvents or solvent mixtures. Dimethyl formamide, diethyl formamide, acetonitrile, acetone, ethanol, methanol, etc. are commonly used organic solvents. Solvothermal reactions are carried out at temperatures greater than the solvent boiling point. Comparatively higher yield is the major advantage of this method. It provides precise control over the shape distribution, size, and crystallinity of material prepared. Synthesis temperature, concentration of reactants and $\mathrm{pH}$ of the solution should be taken into consideration while using this method. However, removal of solvent molecules from the pores is a complex process and is usually achieved by vacuum drying or washing by solvents such as ethanol or methanol. Pan and his co-workers [11] synthesized three-dimensional zinc-based metal-organic framework $\mathrm{Zn}_{2}(\text { bpabdc })_{2}(\mathrm{DMF})_{2}\left(\mathrm{H}_{2} \mathrm{O}\right)_{n}$ under solvothermal condition and used it as a fluorescent sensor for the detection of cadmium ion and nitrobenzene. $\mathrm{Li}$ et al. developed a $\mathrm{Cu}(\mathrm{II})$ metal-organic framework $[\mathrm{Cu}(\mathrm{tdc})$ $\left.\left(\mathrm{H}_{2} \mathrm{O}\right)\right]_{n} \cdot \mathrm{n}(\mathrm{DMA})$, under solvothermal condition with $\mathrm{CuCl}_{2}$ and $\mathrm{H}_{2}$ tdc [12]. Gas adsorption studies showed that the compound can store light hydrocarbons in its desolvated sample. $\mathrm{Du}$ et al. synthesized a microporous zinc (II) MOF material, $\left.\left[\mathrm{H}_{2} \mathrm{~N}\left(\mathrm{CH}_{3}\right)_{2}\right] \cdot\left[\mathrm{Zn}_{4}(\mathrm{abtc})_{2}(\mathrm{ad}) \mathrm{H}_{2} \mathrm{O}\right)\right] \cdot 4 \mathrm{DMF}$ under solvothermal reactions [13]. They used a four-carboxylic acid linker, namely 3,3',5,5'-azobenzene-tetracarboxylic acid and adenine as the organic building blocks to form MOFs. The prepared MOF have shown high selectivity of adsorption of $\mathrm{CO}_{2}$ over $\mathrm{CH}_{4}$ and high heat of adsorption of $\mathrm{CO}_{2}$. Tzitzios et al. [14] prepared a nanoporous, crystalline metal-organic framework by reacting zinc nitrate and terephthalic acid in dimethyl formamide. The synthesis conditions involved supercritical $\mathrm{CO}_{2}$ activation and vacuum out gassing procedures. The activated IRMOF-1 showed fully reversible $\mathrm{H}_{2}$ sorption behavior and gravimetric $\mathrm{H}_{2}$ uptake. Ji et al. [15] synthesized magnesium-based MOF $\left[\mathrm{H}_{3} \mathrm{O}\right]_{2}[\mathrm{Mg}(\mathrm{abtc})$ $\left.(\mathrm{DMI})_{2}\right]$, under solvothermal condition and applied it as a catalyst in cyano silylation of carbonyl compounds. Porous walls exposed with azo-groups were obtained which facilitated its use as a Lewis base catalyst for the cyano silylation of carbonyl compounds.

\section{Mechanochemical synthesis}

Mechanochemical method involves the completion of chemical reaction with the help of mechanical force. Major advantage of mechanochemical synthesis is that the reaction takes place without organic solvents which are carcinogenic, toxic and harmful to environment. In this method, instead of metal salts, metal oxides are usually used as starting materials. Mechanochemical synthesis is simple, economical, and environment friendly. However, only small amount of product is formed in this method. [7, 16, 17]. Chen and his co-workers [18] synthesized indium-based metal organic framework (InOF-1) with excellent water stability mechanochemically and reported as a potential material for $\mathrm{CO}_{2}$ separation and adsorption. Singh et al. [19] developed rare earth-based metal-organic frameworks by mechanical milling of single and mixed rare earth carbonates with benzene 1,3,5-tricarboxylic acid. These MOFs exhibited magnetic properties below $20 \mathrm{~K}$. Yang et al. performed mechanochemical reaction for preparation of $\mathrm{Cu}_{3}(\mathrm{BTC})_{2}$ with emphasis on the effect 
of solvent, starting materials, and grinding parameters in mechanochemical synthesis. The results showed that copper acetate produced better yields compared to copper nitrate as starting material. The existence of small amount of solvent increased the crystallinity, BET and Langmuir surface areas of $\mathrm{Cu}_{3}(\mathrm{BTC})_{2}$ [20].

\section{Electrochemical synthesis}

In electrochemical synthesis, metal ions are provided through anodic dissolution into a reaction mixture containing organic linkers and electrolytes [2]. The major advantage of this method is that the anions associated with metal in salts can be avoided and hence materials produced will be of high purity. Shorter reaction times and milder conditions are required and hence large-scale production of MOFs is possible. Gascon et al. [21] developed several metal-organic frameworks, HKUST-1, ZIF-8, MIL-100(Al), MIL-53(Al), and $\mathrm{NH}_{2}$-MIL-53(Al) by anodic dissolution in an electrochemical cell. They studied the effect of reaction variables such as electrolyte, solvent, temperature and voltage-current density on product yield. They also examined textural properties of the prepared MOFs. Li and his coworkers [22] synthesized fluorescent MOF films of $\left(\mathrm{Zn}_{3}(\mathrm{btc})_{2}\right)$ by applying voltage onto zinc electrodes in 1,3,5-benzenetricarboxylic acid and used for potential applications in identifying nitro explosives with detection limit as low as $0.5 \mathrm{ppm}$ with reusability in successive nitro explosive detection reactions. Campagnol et al. developed MIL-100(Fe) by heating a reaction mixture of 1,3,5-benzenetricarboxylic acid in a 2:1 ethanol:Milli-Q water solvent mixture at high pressure and high temperature in an electrochemical cell [23].

\section{Microwave-assisted synthesis}

Microwave-assisted synthesis offers a swift method for the synthesis of MOFs. Nanosized crystals are produced by irradiation of reaction mixture with microwaves. The advantages of this synthesis are high efficiency, less reaction time, phase selectivity, morphology control, particle size reduction, etc. [24-29]. Fan et al. [30] performed microwave-assisted synthesis of zirconium-based metal-organic frameworks. They compared the yield and porosity by changing quantity of modulator, reaction time and temperature. The reaction was completed in 2-2.5 h in microwave which took $24 \mathrm{~h}$ for completion in solvothermal method. McKinstry et al. [31] synthesized HKUST-1 using ethanol as the solvent by microwave irradiation. Schlesinger and his coworkers [32] compared different synthetic methods such as solvothermal, microwave-assisted, mechanochemical and ultrasonic method for the preparation of $\left[\mathrm{Cu}_{3}(\mathrm{btc})_{2}\left(\mathrm{H}_{2} \mathrm{O}\right)_{3}\right]$. The microwave-assisted solvothermal synthesis was found to be better with BET surface area $1499 \mathrm{~m}^{2} / \mathrm{g}$ and a specific pore volume $0.79 \mathrm{~m}^{2} / \mathrm{g}$.

\section{Sonochemical synthesis}

In this synthesis, a solution of the reaction mixture is subjected to ultrasound ( $20 \mathrm{kHz}-10 \mathrm{MHz}$ ) by which molecules undergo chemical change to produce compounds with novel morphologies and unique properties. Within short reaction time, MOFs with small crystal size can be obtained with sonochemical method. Ultrasonic radiation can produce very high temperatures and pressures in the reaction medium. Advantages of this method are that it is generally rapid, economical, reproducible, and environment friendly [29, 33-35]. Armstrong and his coworkers [36] performed the synthesis of the metal organic framework HKUST-1 sonochemically. They studied various parameters such as reactor volume, reaction time, sonication tip size, sonication amplitude, solvent and reactant concentrations. It was found that sonication amplitude and solvent choice affect the particle size distribution, and yield. Morsali et al. developed a threedimensional cadmium metal-organic framework TMU-7 by ultrasound irradiation [37]. They studied the effects of a variety of factors such as different times of irradiation and various concentrations of initial reagents. Uniform nanoplates were achieved by increasing the time of irradiation. Congo red dye adsorption on these MOFs was efficient due to increase in surface area. Lestari et al. [38] compared electro and sonochemical methods for synthesis of MOF $\left[\mathrm{Zn}_{3}(\mathrm{btc})_{2}\right]$. Sonochemical method produced higher yield and smaller particle size than the electrochemical method.

\section{Stability of MOFs}

Stability is the most crucial factor in the design of MOFs. A MOF must be stable for characterization and for varied application such as sensing, adsorption and catalysis. Stability of MOF means chemical, thermal, hydrothermal and mechanical stabilities. All these stabilities are connected with metal-ligand bond strength. Chemical stability of MOFs can be increased by means of high valence metal ions, such as $\mathrm{Cr}^{3+}, \mathrm{Fe}^{3+}$, and $\mathrm{Zr}^{4+}$ and by the interactions between soft ligands such as triazolates, imidazolates and tetrazolates. Other nitrogen containing heterocycles can also be used with softer metal ions such as $\mathrm{Zn}^{2+}, \mathrm{Co}^{2+}$. The relative stabilities of azolate MOFs are due to strong metal-nitrogen bonds. Divalent metal ions create strong bonds with nitrogen linkers, whereas trivalent metal ions generate strong bonds with oxygen anion-terminated linkers. These MOFs show excellent stability in water $[39,40]$. Thermal degradation of MOFs occurs due to node-linker bond breakage, followed by linker combustion. The thermal stability can be increased 
by oxy-anion-terminated linkers with higher-valency metal centers. TGA and PXRD can be used to analyze thermal stability. Hydro-thermal stability means stability in the presence of moisture at elevated temperatures. Intermolecular or intramolecular forces, hydrophobic functional groups, perfluorinated linkers, etc. within MOF structure can increase the hydrothermal stability [41-43]. Mechanical stability of MOFs is connected to their extra-ordinary porosity. Mechanical stability decreases with the increase of porosity. Solventfilled MOFs are found to be mechanically more stable than MOFs with empty pores [44-48].

\section{MOFs as heterogeneous catalysts}

MOFs have been employed in a wide variety of applications such as gas storage, gas separation, catalysis, luminescence, drug delivery, etc. They are found to be highly useful in catalysis due to its porous nature. Heterogeneous catalysis is one of the vital solutions of our developed society, as many chemical processes can be brought about cost effectively using heterogeneous catalyst. MOFs possess fascinating and tailorable properties such as high surface area, permanent porosity and multifunctional ligands. The most important characteristic responsible for their catalytic ability is lack of non-accessible volume. Advantages of MOFs as heterogeneous catalyst are enhanced catalyst reactivity, flexibility, easy tunability, etc. These catalysts possess size, shape, and enantioselectivity. However, due to their low chemical and thermal stability, these are not applicable for reactions that require severe conditions $[3,7,49,50]$. MOFs were used as a catalyst or catalyst supports for a diversity of organic transformations including Friedel-Crafts reactions [51-55], Knoevenagel condensation [56-60], aldol condensation [61-63], oxidation [64-67], coupling reactions [68-75], cyano silylation $[15,76,77]$, carbon dioxide fixation [78, 79], etc (Fig. 1).

\section{Friedel-Crafts reaction}

Friedel-Crafts reaction of aromatic compounds is a key process for the preparation of several intermediates in petroleum industry, pharmaceutical, fragrance, flavor, dye and agrochemical industries. They are generally catalyzed by Lewis acids such as $\mathrm{AlCl}_{3}, \mathrm{FeCl}_{3}, \mathrm{ZnCl}_{2}$ and strong mineral acids such as HF. However, catalyst recovery, recycling and product separation are difficult with these catalysts. As these catalysts are moisture sensitive, dry atmosphere is necessary to carry out these reactions. To avoid the drawbacks of homogeneous catalysts, numerous solid acid catalysts have been investigated for the Friedel-Crafts reactions [79-83].

Zhu and co-workers [51] developed a novel urea-containing metal-organic framework and used for Friedel-Crafts

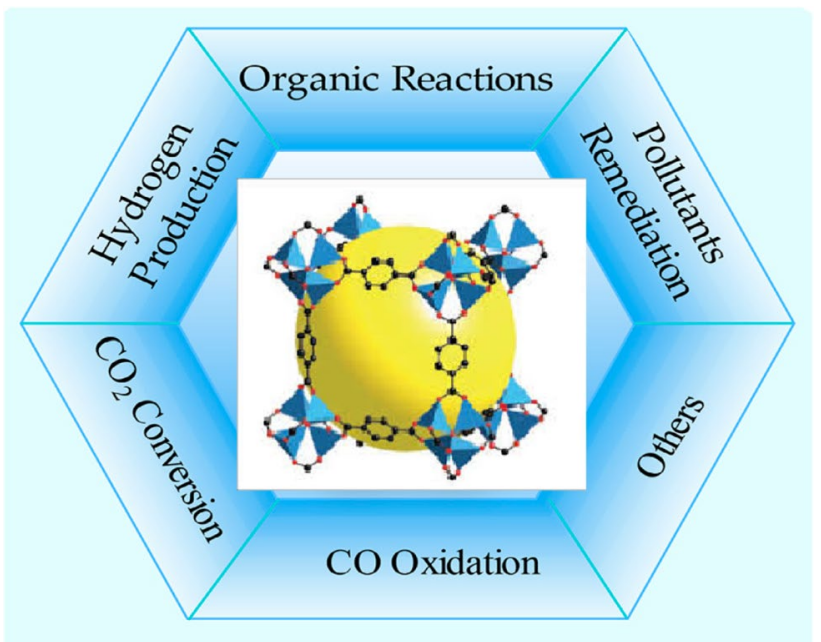

Fig. 1 Versatile applications of MOFs in heterogeneous catalysis

reaction of nitrostyrenes and indoles. They were found to be efficient with excellent product yields at low catalyst loadings. The catalyst demonstrated higher catalytic activity compared to its homogenous urea counterparts. Calleja and coworkers [52] investigated the catalytic properties of $\mathrm{Cu}$ MOF-74 material for the Friedel-Crafts acylation of anisole with acetyl chloride to form methoxyacetophenone. They studied the effect of reaction parameters like the acylating agent, solvent and the reaction temperature. The catalytic activity of $\mathrm{Cu}-\mathrm{MOF}-74$ is found to be more active compared to HKUST-1(Cu-MOF), H-ZSM-5 and BETA (aluminum-containing microporous zeolites) and Al-MCM-41 (mesoporous ordered materials). Cu-MOF-74 also showed high stability and reusability. Dhakshinamoorthy et al. compared the catalytic activity of $\mathrm{Cu}_{3}(\mathrm{btc})_{2}, \mathrm{Fe}(\mathrm{btc}), \mathrm{Zr}(\mathrm{bdc})$ and $\mathrm{Zr}(\mathrm{pdc})$ in Friedel-Crafts alkylation reaction of indole with $\beta$-nitrostyrene [53]. $\mathrm{Cu}_{3}(\mathrm{btc})_{2}$ exhibited higher activity under the optimized reaction conditions without leaching of active sites when performed in different solvents at different temperatures. The catalyst was found to be reusable for four cycles with nominal decrease in its activity and retention of crystalline structure. Phan et al. [54] developed MOF- 5 by the reaction between zinc nitrate hexahydrate and 1,4-benzene dicarboxylic acid in $N, N_{-}$-diethyl formamide under solvothermal method for Friedel-Crafts benzylation of toluene. $p$-Benzyl toluene was obtained as major product and $o$-benzyl toluene as the minor product under mild conditions. The catalyst was found to be reusable after several catalytic runs. Nguyen et al. [55] synthesized IRMOF-8 under solvothermal condition by the reaction between zinc nitrate tetrahydrate and 2,6-naphthalenedicarboxylic acid in $N, N^{\prime}$ dimethylformamide. They used IRMOF-8 for Friedel-Crafts acylation of toluene with benzoyl chloride to form $p$-benzoyl toluene as the major product and $o$-benzoyl toluene as 
by-product. The reaction was carried out at $80{ }^{\circ} \mathrm{C}$ for $6 \mathrm{~h}$ with 5 mol\% IRMOF-8 catalyst with toluene. $50 \%$ conversion and $80 \%$ selectivity to $p$-benzoyl toluene was observed in the absence of inert atmosphere. IRMOF- 8 showed high stability, selectivity and reusability. Other MOFs reported as Friedel-Crafts catalysts is given in Table 1.

\section{Knoevenagel condensation}

Gascon et al. [56] developed metal-organic frameworks with non-coordinated amino groups, IRMOF-3 and amino-functionalized MIL-53, for Knoevenagel condensation of ethyl acetoacetate and ethyl cyanoacetate with benzaldehyde. IRMOF-3 displayed 100\% selectivity in Knoevenagel condensation. In IRMOF-3 catalysts, aniline-like amino group enhanced the basicity when integrated inside the catalyst structure. The IRMOF-3 catalyst was found to be stable and reusable under reaction conditions.

Hartmann and coworker [57] synthesized three different MOFs, Fe-MIL-101-NH 2 , Al-MIL-101- $\mathrm{NH}_{2}$ and CAU-1. They explored these MOFs in the Knoevenagel condensation of ethyl cyanoacetate and malononitrile with benzaldehyde. The products benzylidene malononitrile and ethyl acyanocinnamate were formed with almost cent percent selectivities with yields of 90-95\% after $3 \mathrm{~h}$. The reaction with CAU-1 proceeds slower in contrast to the amino-MIL-101 derivatives. Yang et al. [58] explored the catalytic efficiency of UiO-66- $\mathrm{NH}_{2}$ in Knoevenagel condensation. They carried out the condensation of benzaldehyde with malononitrile and ethyl cyanoacetate in polar solvents such as DMSO, DMF and ethanol. The UiO-66- $\mathrm{NH}_{2}$ exhibited higher catalytic activity on comparison with the isostructural aminofree MOF (UiO-66). The catalyst was found to be reusable and stable after several cycles. Xamena et al. [59] considered the catalytic activity of IRMOF-3 and MOF-5 in Knoevenagel condensation of ethyl cyanoacetate and benzaldehyde.
In their work, they made emphasis on the effect of different synthetic procedures of IRMOF- 3 and MOF- 5 on the Knoevenagel condensation reaction. Callega et al. [60] studied the catalytic activity and stability of amino-based MIL-53(Al) materials in Knoevenagel condensation of malononitrile with benzaldehyde. They modified the amine content using different ratios of 2-amino-benzene-1,4-dicarboxylic acid $\left(\mathrm{NH}_{2}-\mathrm{BDC}\right)$ and benzene-1,4-dicarboxylic acid as organic ligands during synthesis. The MIL-53(Al) material with equimolar amounts of $\mathrm{BDC}$ and $\mathrm{NH}_{2}$-BDC exhibited more catalytic performance on comparison with other amino-containing MOFs such as UiO-66- $\mathrm{NH}_{2}$, MIL-101(Al)- $\mathrm{NH}_{2}$ and IRMOF-3 as well as Na-exchanged beta zeolite.

\section{Aldol condensation}

MOFs have been successfully used by different groups in aldol condensation reactions. Koner et al. [61] used an alkaline earth MOF compound, $[\mathrm{Ba}(\mathrm{pdc})]_{n}$ for the aldol reaction of various aromatic aldehydes with cyclohexanone and acetone. They compared catalytic activity in THF, THF/water and solvent-less condition. They found that with increase in the temperature, $\beta$-aldol was converted into benzylideneketone. High product formation is observed for electron-withdrawing groups at ortho and para positions of benzaldehyde, whereas lower conversion for electron-donating groups. The catalyst maintained structural integrity and stability after several catalytic reactions. Pathan et al. [62] developed a proficient methodology for the green synthesis of pyrimidine-chalcone using acetophenone and formyl pyrimidines in the presence of $\left[\mathrm{Cu}_{3}(\mathrm{btc})_{2}\left(\mathrm{H}_{2} \mathrm{O}\right)_{3}\right.$. Though $\mathrm{Cu}_{3}(\mathrm{btc})_{2}$ was a strong Lewis acid, the catalytic reaction afforded only a negligible conversion on addition of $\mathrm{H}_{2} \mathrm{SO}_{4}$ to reaction mixture. The catalyst was found to be reusable up to 11 th cycle. Kikhtyanin et al. [63] used several MOF like Basosiv M050, Basolite Z1200, (Cu-btc) and (Fe-btc) in aldol condensation
Table 1 MOFs reported as Friedel-Crafts catalysts

\begin{tabular}{lll}
\hline Type of MOF catalyst & Friedel-Crafts reaction & References \\
\hline CuMOF (MOF-891) & Synthesis of bis(indolyl)methanes & Nguyen et al. [84] \\
HPW @ Zr-BTC & Acylation of anisole with benzoyl chloride & Ullah et al. [85] \\
ZnMOF & Alkylation of indoles with nitroalkenes & Rao et al. [86] \\
Al-based MIL-53 & Alkylation of benzene with ethanol & Rahmani et al. [87] \\
MIL-53(Al) & Acylation of indole with benzoyl chloride & Yan et al. [88] \\
Cu-MOF-74 & Acylation of anisole & Calleja et al. [89] \\
Zr-MOF & Benzoylation of arenes & Doan et al. [90] \\
Urea containing 2D MOF & Friedel-Crafts reaction of indoles and nitrostryenes & Zhu et al. [51] \\
MIL-53(Al) @ SiO $@ \mathrm{Fe}_{3} \mathrm{O}_{4}$ & Acylation of 2-methylindole with benzoyl chloride & Jiang et al. [91] \\
$\mathrm{Zn} \mathrm{MOF}$ & Alkylation of toluene with benzyl bromide & Farzaneh et al. [92] \\
IRMOF-3-PI-RuCl & Alkylation of indoles and pyrroles & Khalil et al. [93] \\
Sulfonated $\mathrm{Zr}-\mathrm{MOF}_{\mathrm{Cu}}$ & Acylation of $p$-xylene with benzoyl chloride & Chung et al. [94] \\
$\mathrm{Cu}_{4} \mathrm{I}_{4}$-MOF & Alkylation of indoles with acetals & Zhu et al. [95] \\
\hline
\end{tabular}


of acetone and furfural. These reactions were carried out in Parr stirred autoclave under batch conditions at $100{ }^{\circ} \mathrm{C}$. Basosiv M050 and Basolite Z1200 showed insignificant activity, whereas $\mathrm{Cu}$-basolite (Cu-btc) and $\mathrm{Fe}$-basolite (Febtc) were active catalysts for the reaction. Acidic centers were attributed as active sites for the aldol condensation over MOFs.

\section{Oxidations}

MOFs have been attempted by several groups for oxidation reactions recently. Dhakshinamoorthy et al. [64] studied some metal-organic frameworks for the conversion of silane into silanol using either t-butyl hydroperoxide or water as oxidants. $\mathrm{Cu}_{3}(\mathrm{btc})_{2}$ exhibited a comparable activity with $\mathrm{Zr}(\mathrm{bdc})$, while the activity of $\mathrm{Fe}(\mathrm{btc})$ is lower than $\mathrm{Cu}_{3}(\mathrm{btc})_{2}$ using TBHP as oxidant. On the other hand, $\mathrm{Cu}_{3}(\mathrm{btc})_{2}$ showed complete conversion with high selectivity with water as oxidant, but other MOFs like $\mathrm{Fe}(\mathrm{btc})$ and $\mathrm{Zr}$ (bdc) are inactive under identical reaction conditions. Kholdeevaa and coworkers [65] prepared Fe- and Cr-containing MOFs, MIL-100 and MIL-101 by solvothermal method and compared the catalytic activities in allylic oxidation of cyclohexene and terpenes with molecular oxygen and oxidation of anthracene with tert-butyl hydroperoxide. In the oxidation of alkenes, Fe-containing MOFs produced unsaturated alcohols, whereas Cr-based MOFs gave unsaturated ketones. 100\% selectivity was observed for both Cr-MOFs and Fe-MIL-101 with $92-100 \%$ anthracene conversion. The stability of MOF enhanced in the order, Fe-MIL-101 $<$ Fe-MIL-100 $<$ CrMIL-100, Cr-MIL-101. Kholdeeva et al. [66] also studied the catalytic efficiency of Fe-MIL-101 and Cr-MIL-101 MOFs in the oxidation of $\alpha$-pinene and cyclohexene at solvent-free conditions. The catalysts performed alkene oxidation at mild conditions and attained allylic oxidation products. Cr-MIL-101 showed selectivity towards $\alpha, \beta-$ unsaturated ketones whereas Fe-MIL-101 showed selectivity towards 2-cyclohexene-1-ol at $40{ }^{\circ} \mathrm{C}$. Leaching of iron to the solution occured in case of Fe-MIL-101 at $50-60{ }^{\circ} \mathrm{C}$, leading to cyclohexenyl hydroperoxide. Both catalysts showed better reusability under optimum conditions. Vodyankina et al. [67] investigated the catalytic activity of chromiumbased metal-organic frameworks, MIL-101 and MIL-100 in oxidation of propylene glycol using tert-butyl hydroperoxide as oxidant. Hydroxyl acetone was obtained as major product, while acetic acid and acetaldehyde were the minor products.

\section{Coupling reactions}

Coupling reactions are favorite methods for organic chemists in various organic transformations and fine chemical synthesis. Phan et al. [68] used a decidedly porous metal-organic framework, MOF-199 as heterogeneous catalyst for Ullmann-type reaction between phenols and aryl iodides forming diaryl ethers. The product yield was $82 \%$ after $6 \mathrm{~h}$ at $120{ }^{\circ} \mathrm{C}$. MOF-199 catalyst was reusable without noteworthy deterioration in catalytic activity. Chen et al. [69] prepared MOF-253 by hydrothermal reaction of $\mathrm{AlCl}_{3} \cdot 6 \mathrm{H}_{2} \mathrm{O}, 2,2^{\prime}$-bipyridine-5,5-dicarboxylic acid, glacial acetic acid, and $N, N_{-}$-dimethyl formamide at $120^{\circ} \mathrm{C}$ for $24 \mathrm{~h}$. Palladium chloride was successfully immobilized on MOF-253, by post-synthetic adaptation. The prepared MOF showed catalytic activity towards Ullmann homocoupling and Suzuki-Miyaura cross-coupling. MOF-253. $\mathrm{PdCl}_{2}$ showed higher activity compared to other homogeneous $\mathrm{Pd}(\mathrm{bpy}) \mathrm{Cl}_{2}$ and $\mathrm{PdCl}_{2}\left(\mathrm{CH}_{3} \mathrm{CN}\right)_{2}$. The superior catalytic performances of metal ions were attributed to charge transfer between metals and adjacent ligands in the catalyst. Nguyen et al. [70] prepared a metal-organic framework $\mathrm{Fe}_{3} \mathrm{O}$ (BPDC) $)_{3}$ under solvothermal method and used to produce azole derivatives by direct $\mathrm{C}-\mathrm{N}$ coupling of azoles with ethers by oxidative $\mathrm{C}-\mathrm{H}$ activation. The leaching studies found that the leached active iron species contributed negligibly to the production of the preferred azole product. The MOF-based catalyst was reused many times without difference in catalytic efficiency. Dhakshinamoorthy et al. [71] explored the catalytic activity of $\mathrm{Cu}_{3}(\mathrm{btc})_{2}$ for the dehydrogenative coupling of dimethylphenylsilane with phenol at tolerant circumstances. They observed that $\mathrm{Cu}_{3}(\mathrm{btc})_{2}$ exhibited higher stability and activity compared to other MOFs $\mathrm{Fe}(\mathrm{BTC}), \mathrm{MIL}-101(\mathrm{Cr})$ and UiO-66(Zr) in cross-coupling between dimethyl phenyl silane and phenol. Reusability studies showed that $\mathrm{Cu}_{3}(\mathrm{btc})_{2}$ can be reused with minimum deterioration in activity. Brown et al. [72] prepared a series of MOFs, $\mathrm{Zn}_{4} \mathrm{O}\left(\mathrm{bdc}-\mathrm{NH}_{2}\right)_{n}(\mathrm{bdc})_{(3-n)}(n=3,2.4,1.8,1.2$, $0.9,0.75,0.6,0.3$, and 0.15 ). They modified each compound post synthetically and metalated with $\mathrm{Pd}$, providing the palladium functionalized framework. They exhibited greater activity, selectivity and recyclability in Heck coupling. Corma and co-workers [73] found that copper-containing MOFs were stable, active and reusable solid catalysts for coupling reactions of amines, aldehydes and alkynes forming the consequent propargylamines. Dang et al. [74] prepared Cu-MOF-74 by a solvothermal method and used it for the synthesis of indolizines through aldehyde-amine-alkyne three-component coupling. Cu-MOF-74 showed superior catalytic activity than other $\mathrm{Cu}-\mathrm{MOF}$ in three-component coupling reaction. The $\mathrm{Cu}-\mathrm{MOF}$ catalyst is found to be reusable without significant change in catalytic activity. Zhang et al. [75] synthesized Pd nanoparticles supported on scandium metal-organic frameworks through microwave-assisted impregnation technique. The prepared Pd-Sc btc nano MOFs were better catalysts compared to active carbon supported Pd catalysts in the Suzuki cross-coupling reaction. The catalyst exhibited negligible metal leaching with significant activity in several catalytic runs. Table 2 summarizes other 
Table 2 Various MOFs reported for coupling reactions in recent literature

\begin{tabular}{lll}
\hline MOF catalyst used & Coupling reaction & References \\
\hline Cu-BDC MOF & Suzuki coupling & Rostamnia et al. [96] \\
UiO-68Se & Aerobic cross-dehydrogenative coupling & Zhang et al. [97] \\
Pd(II)-porphyrinic MOF & Heck coupling & Chen et al. [98] \\
Pd NPs supported on UiO-66-NH & Suzuki cross-coupling & Kardanpour et al. [99] \\
Pd@MIL-101 & Biginelli and Hantzsch coupling & Rostamnia et al. [100] \\
NPC-Pd MOF & Suzuki-Miyaura coupling & Zhang et al. [101] \\
Transition metal-free MOF & Oxidative coupling of amines & Qiu et al. [102] \\
$\mathrm{Cu}(4-\text { ba })_{2}$ ] $($ solvent $\left.)\right\}_{n}$ & Chan-Lam coupling, Suzuki-Miyoura & Wang et al. [103] \\
$\mathrm{Cu}^{2+}-\mathrm{M}^{\prime} \mathrm{MOF}$ ZJU-22 & coupling, Heck coupling & \\
\hline
\end{tabular}

MOFs that have been used as catalysts for various coupling reactions.

\section{Cyano silylation}

Bharadwaj and co-workers [76] carried out a reaction between an aqueous solution of $\mathrm{Zn}\left(\mathrm{NO}_{3}\right)_{2} \cdot 6 \mathrm{H}_{2} \mathrm{O}$ and tetraethylammonium salt of the tripodal ligand tris-(4-carboxy2-phenoxyethyl)amine $\left(\mathrm{ptaH}_{3}\right)$ at room temperature. The prepared MOF with coordinatively unsaturated $\mathrm{Zn}$ (II) centers were used for Knoevenagel condensation and cyanosilylation reactions successfully. Li et al. [15] synthesized magnesium compound-based 3,3',5,5'-azobenzene-tetracarboxylic acid $\left(\mathrm{H}_{3} \mathrm{O}\right)_{2}\left[\mathrm{Mg}(\mathrm{abtc})(\mathrm{DMI})_{2}\right]_{n}$ under solvothermal condition and used as heterogeneous catalyst for the cyanosilylation of carbonyl compounds in solvent-less situation. Significant loss in activity was not observed on reuse. Voort et al. [77] prepared a homochiral vanadium MOF in solvothermal environment. The prepared MOF showed BET surface areas of $574 \mathrm{~m}^{2} \mathrm{~g}^{-1}$ and exhibited $\mathrm{H}_{2}$ adsorption capacity and $\mathrm{CO}_{2}$ uptake. They used it as asymmetric catalyst in solvent-free cyanosilylation. The catalyst was found to be recyclable and reusable for several times. Other catalysts reported for cyanosilylation reactions include $\mathrm{Mn}_{3}\left[\left(\mathrm{Mn}_{4} \mathrm{Cl}\right)_{3}(\mathrm{BTT})_{8}\left(\mathrm{CH}_{3} \mathrm{OH}\right)_{10}\right]_{2}$ for cyanosilylation of aromatic aldehydes and ketones [105] and $\mathrm{Cu}_{3}(\mathrm{BTC})_{2}[106]$.

\section{$\mathrm{CO}_{2}$ fixation}

Babu and co-workers [78] prepared In(III) MOFs with $\mathrm{N}$-donor ligands and carboxylic acids and used as a solid catalyst in $\mathrm{CO}_{2}$-epoxide cycloaddition reactions. Among the prepared systems, the one-dimensional MOFs containing unsaturated metal centers showed better catalytic efficiency than the two- and three-dimensional MOFs. The same group [79] also prepared a highly porous 3D MOF
$\left[\mathrm{Zn}_{4} \mathrm{O}(2,6-\mathrm{NDC})(\mathrm{BTB})_{4 / 3}\right](\mathrm{MOF}-205)$ under microwave method and used its catalytic activity for the $\mathrm{CO}_{2}$-epoxide coupling reactions to generate five-membered cyclic carbonates at room temperature in solvent-less conditions. They found that the microwave-assisted method is better compared to conventional solvothermal method for catalyst synthesis. The catalyst is found to be reusable up to five cycles. Other MOF catalysts reported in recent literature include MOF505 [107], triazole containing CuMOF [108] and a CuMOF containing linear tetracarboxylic acid ligand, $\mathrm{H}_{4} \mathrm{~L}$, with a pendent amine moiety [109].

Interestingly, MOFs and MOF-based catalysts have been used for a wide variety of organic transformations leading to fine chemical synthesis as well as environmental management recently. A summary of the versatile reactions and catalysts is tabulated in Table 3 .

\section{Conclusions}

In recent years, MOF materials have become increasingly relevant in chemical industry. The field has been expanding suddenly with the aim of developing new compounds with new structures and fascinating properties. Though different synthetic methods and unlimited number of MOFs with different combinations of linker molecules and metal ions are possible, divalent metal ions with nitrogen linkers and trivalent metal ions with oxygen anion-terminated linkers show comparatively excellent stability. Greener synthesis techniques such as microwave- and sono-assisted methods are gaining momentum. The application of MOFs as heterogeneous catalysts in organic transformations is a developing area of research. They have been widely employed for several transformations such as Friedel-Crafts reactions, condensation reactions, oxidations, coupling reactions, carbon 
Table 3 Reactions catalyzed by MOFs and MOF-based catalysts

\begin{tabular}{|c|c|c|}
\hline MOF catalyst & Type of reaction & References \\
\hline chiral (salen)Mn MOF & Olefin epoxidation & Cho et al. [110] \\
\hline $\mathrm{Cu}_{3}(\mathrm{btc})_{2}$ & rearrangement of $\alpha$-pinene oxide, cyclization of citronellal & Alaerts et al. [111] \\
\hline$\left[\mathrm{Cu}_{2}(\mathrm{BTC})_{4 / 3}\left(\mathrm{H}_{2} \mathrm{O}\right)_{2}\right]_{6}\left[\mathrm{H}_{n} \mathrm{XM}_{12} \mathrm{O}_{40}\right] \cdot\left(\mathrm{C}_{4} \mathrm{H}_{12} \mathrm{~N}\right)_{2}$ & Hydrolysis of esters & Sun et al. [112] \\
\hline$\left[\mathrm{Cd}(\mu-\mathrm{Cl})_{2}\right]_{n} \mathrm{MOF}$ & Asymmetric catalysis & Wu et al. [113] \\
\hline Zr-terephthalate MOF & Cross-aldol condensation & Vermoortele et al. [114] \\
\hline $\mathrm{Zr}$ metalloporphyrin PCN-222 & Oxidation of pyrogallol & Feng et al. [115] \\
\hline Basolite C 300 & Friedländer reaction & Pérez-Mayoral et al. [116] \\
\hline$\left[\mathrm{Cu}_{3}\left(\mathrm{C}_{9} \mathrm{H}_{3} \mathrm{O}_{6}\right)_{2}\right]_{4}\left[\left\{\left(\mathrm{CH}_{3}\right) 4 \mathrm{~N}\right\}_{4} \mathrm{CuPW}_{11} \mathrm{O}_{39} \mathrm{H}\right]$ & Oxidation of thiols & Song et al. [117] \\
\hline $\mathrm{Zn}_{5} \mathrm{Cl}_{4}(\mathrm{BTDD})_{3}$ & Olefin polymerization & Comito et al. [118] \\
\hline Fe- and Co-functionalized MOFs & Olefin hydrogenation & Manna et al. [119] \\
\hline Cobalt porphyrin MOF & $\mathrm{CO}_{2}$ reduction & Lin et al. [120] \\
\hline PCN-222/MOF-545 & Hotooxidation of 2-chloroethyl ethyl sulfide & Liu et al. [121] \\
\hline Porphyrin-based Zr-MOF & $\begin{array}{l}\text { Etoxification of dimethyl 4-nitrophenyl phosphate and 2-chloro- } \\
\text { ethyl ethyl sulfide }\end{array}$ & Liu et al. [122] \\
\hline Lithium-alkoxide doped Zr-MOF & Self-detoxifying filters & López-Maya et al. [123] \\
\hline $\mathrm{Ni}-\mathrm{S}$ electrocatalyst on MOF scaffolds & Electrochemical hydrogen evolution & Hod et al. [124] \\
\hline InPF-110 & Strecker reaction of ketones & Reinares-Fisac et al. [125] \\
\hline $\mathrm{Zr}_{6} \mathrm{O}_{4}(\mathrm{OH})_{4}(\mathrm{bpydc})_{6}$ & Arene $\mathrm{C}-\mathrm{H}$ borylation & Gonzalez et al. [126] \\
\hline Hf-NU-1000 & 1-Hexene polymerization & Klet et al. [127] \\
\hline Hf MOF & Tandem oxidation and functionalization of styrene & Beyzavi et al. [128] \\
\hline Co@NH2-MIL-125(Ti) & $\mathrm{H}_{2}$ production & Nasalevich et al. [129] \\
\hline MOOF-based CoP/reduced graphene oxide & Water splitting & Jiao et al. [130] \\
\hline Core-shell Pd@IRMOF-3 nanostructures & Cascade reactions & Zhao et al. [131] \\
\hline MOF-confinedPd@ Co NPs & Hydrolytic dehydrogenation of ammonia borane & Chen et al. [132] \\
\hline $\mathrm{Cu}_{3}(\mathrm{BTC})_{2}$ & Aerobic epoxidation of olefins, oxidation of alcohols & Qi et al. [133] \\
\hline Mo-NU-1000 & Cyclohexene epoxidation & Noh et al. [134] \\
\hline Homochiral MOF & Cyanohydrin synthesis & Mo et al. [135] \\
\hline $\mathrm{Zr}-\mathrm{MOF}$ with $\mathrm{Me}_{2} \mathrm{Mg}$ & Hydroboration and hydroamination & Manna et al. [136] \\
\hline Co nanoparticle-embedded carbon @ $\mathrm{Co}_{9} \mathrm{~S}_{8}$ & Oxygen reduction & Hu et al. [137] \\
\hline $\mathrm{N}$-doped CNTs derived from MOF & Oxygen electrocatalyst & Xia et al. [138] \\
\hline Ni-Zr-NU-1000 & Gas-phase hydrogenation & Li et al. [139] \\
\hline Fe-porphyrin-MOF & Electrochemical reduction of $\mathrm{CO}_{2}$ & Hod et al. [140] \\
\hline Pdnanocubes@ZIF-8 & Hydrogenation of olefins & Yang et al. [141] \\
\hline Hf-NU-1000 & $\mathrm{CO}_{2}$ fixation, enantioretentive epoxide activation & Beyzavi et al. [142] \\
\hline MIL-101-Cr-SO 3 H·Al(III) & Fixed-bed reactions & Li et al. [143] \\
\hline $\mathrm{Mn}-\mathrm{Zr}-\mathrm{MOF}$ & Photocatalytic $\mathrm{CO}_{2}$ reduction & Fei et al. [144] \\
\hline BINAP-based MOFs & Pauson-Khand reaction between 1,6-enynes and carbon monoxide & Sawano et al. [145] \\
\hline
\end{tabular}

dioxide fixation, etc. to name a few. Recently, the thrust has shifted to shape selective catalysis owing to their regular structure and porosity.

\section{Complaince with ethical standards}

Conflict of interest On behalf of all authors, the corresponding author states that there is no conflict of interest.

Open Access This article is distributed under the terms of the Creative Commons Attribution 4.0 International License (http://creativeco mmons.org/licenses/by/4.0/), which permits unrestricted use, distribution, and reproduction in any medium, provided you give appropriate credit to the original author(s) and the source, provide a link to the Creative Commons license, and indicate if changes were made.

\section{References}

1. Dey, C., Kundu, T., Biswal, B.P., Mallick, A., Banerjee, R.: Crystalline metal-organic frameworks (MOFs): synthesis, structure and functions. Acta Crystallogr. 70, 3-10 (2014) 
2. Lee, Y., Kim, J., Ahn, W.: Synthesis of metal organic frameworks: a mini review. Korean J. Chem. Eng. 30, 1667-1680 (2013)

3. Czaja, A.U., Trukhan, N., Muller, U.: Industrial applications of metal-organic frameworks. Chem. Soc. Rev. 38, 1284-1293 (2009)

4. Ferey, G.: Some suggested perspectives for multifunctional hybrid porous solids. Dalton Trans. 23, 4400-4415 (2009)

5. Kuppler, R.J., Timmons, D.J., Fang, Q., Li, J., Makal, T.A., Young, M.D., Yuan, D., Zhao, D., Zhuang, W., Zhou, H.: Potential applications of metal-organic frameworks. Coord. Chem. Rev. 253, 3042-3066 (2009)

6. Kitagawa, S., Kitaura, R., Noro, S.: Functional porous coordination polymers. Angew. Chem. Int. Ed. 43, 2334-2375 (2004)

7. Isaeva, V.I., Kustov, L.M.: The application of metal-organic frameworks in catalysis (Review). Pet. Chem. 50, 167-180 (2010)

8. Farrusseng, D., Aguado, S., Pinel, C.: Metal-organic frameworks: opportunities for catalysis. Angew. Chem. Int. Ed. 48, 7502-7513 (2009)

9. Murinzi, T.W., Hosten, E., Watkins, G.M.: Synthesis and characterization of a cobalt-2,6-pyridinedicarboxylate MOF with potential application in electrochemical sensing. Polyhedron 137, 188-196 (2017)

10. Wang, G., Li, Z., Jia, H., Hu, N., Xu, J.: Metal-organic frameworks based on the pyridine-2,3-dicarboxylate and a flexible bispyridyl ligand: syntheses, structures, and photoluminescence. CrystEngComm 11, 292-297 (2009)

11. Pan, Y., Wang, J., Guo, X., Liu, X., Tang, X., Zhang, H.: A new three-dimensional zinc-based metal-organic framework as a fluorescent sensor for detection of cadmium ion and nitrobenzene. J. Colloid Interface Sci. 513, 418-426 (2018)

12. Li, W., Guo, Y., Zhang, W.: A porous $\mathrm{Cu}(\mathrm{II})$ metal-organic framework: synthesis, crystal structure and gas adsorption properties. J. Mol. Struct. 1143, 20-22 (2017)

13. Du, J., Zou, G.: A novel microporous zinc(II) metal-organic framework with highly selectivity adsorption of $\mathrm{CO}_{2}$ over $\mathrm{CH}_{4}$. Inorg. Chem. Commun. 69, 20-23 (2016)

14. Tzitzios, V., Kostoglou, N., Giannouri, M., Basina, G., Tampaxis, C., Charalambopoulou, G., Steriotis, T., Polychronopoulou, K., Doumanidis, C., Mitterer, C., Rebholz, C.: Solvothermal synthesis, nanostructural characterization and gas cryo-adsorption studies in a metal-organic framework (IRMOF-1) material. Int. J. Hydrogen Energy 42, 23899-23907 (2017)

15. Li, Y., Zhang, L., Ji, W.: Synthesis, characterization, crystal structure of magnesium compound based 3, 3', 5, 5'-azobenzentetracarboxylic acid and application as high-performance heterogeneous catalyst for cyanosilylation. J. Mol. Struct. 1133, 607-614 (2017)

16. Klimakow, M., Klobes, P., Rademann, K., Emmerling, F.: Characterization of mechanochemically synthesized MOFs. Microporous Mesoporous Mater. 154, 113-118 (2012)

17. Fernandez-Bertran, J.F.: Mechanochemistry: an overview. Pure Appl. Chem. 71, 581-586 (1999)

18. Chen, Y., Xiao, J., Lv, D., Huang, T., Xa, F., Sun, X.: Highly efficient mechanochemical synthesis of an indium based metalorganic framework with excellent water stability. Chem. Eng. Sci. 158, 539-544 (2017)

19. Singh, N.K., Gupta, S., Pecharsky, V.K., Balema, V.P.: Solventfree mechanochemical synthesis and magnetic properties of rare-earth based metal-organic frameworks. J Alloys Compd 696, 118-122 (2017)

20. Yang, H., Orefuwa, S., Goudy, A.: Study of mechanochemical synthesis in the formation of the metal-organic framework $\mathrm{Cu}_{3}$ (BTC) $)_{2}$ for hydrogen storage. Microporous Mesoporous Mater. 143, 37-45 (2011)
21. Joaristi, A.M., Juan-Alcañiz, J., Serra-Crespo, P., Kapteijn, F., Gascon, J.: Electrochemical synthesis of some archetypical $\mathrm{Zn}^{2+}$ $\mathrm{Cu}^{2+}$, and $\mathrm{Al}^{3+}$ metal organic frameworks. Cryst. Growth Des. 12, 3489-3498 (2012)

22. Li, W., Lü, J., Gao, S., Li, Q., Cao, R.: Electrochemical preparation of metal-organic framework films for fast detection of nitro explosives. J. Mater. Chem. A. 2, 19473-19478 (2014)

23. Campagnol, N., Van Assche, T., Boudewijns, T., Denayer, J., Binnemans, K., De Vos, D., Fransaer, J.: High pressure, high temperature electrochemical synthesis of metal-organic frameworks: films of MIL-100 (Fe) and HKUST-1 in different morphologies. J. Mater. Chem. A. 1, 5827-5830 (2013)

24. Sun, Y., Zhou, H.: Recent progress in the synthesis of metalorganic frameworks Sci. Technol. Adv. Mater. 16, 054202 (2015)

25. Khan, N.A., Jhung, S.H.: Synthesis of metal-organic frameworks (MOFs) with microwave or ultrasound: rapid reaction, phase-selectivity, and size reduction. Coord. Chem. Reviews. 285, 11-23 (2015)

26. Zhu, G., Li, X., Wang, H., Zhang, L.: Microwave assisted synthesis of reduced graphene oxide incorporated MOF-derived $\mathrm{ZnO}$ composites for photocatalytic application. Catal. Commun. 88, 5-8 (2017)

27. Zhu, W., Liu, P., Xiao, S., Wang, W., Zhang, D., Li, H.: Microwave-assisted synthesis of Ag-doped MOFs-like organotitanium polymer with high activity in visible-light driven photocatalytic NO oxidization. Appl. Catal B Environ. 172-173, 46-51 (2015)

28. da Silva, C.T.P., Safadi, B.N., Moises, M.P.: Synthesis of ZnBTC metal organic framework assisted by a home microwave oven and their unusual morphologies. Mater. Lett. 182, 231-234 (2016)

29. Khan, N.A., Jhung, S.H.: Synthesis of metal-organic frameworks (MOFs) with microwave or ultrasound: rapid reaction, phaseselectivity, and size reduction. Coord. Chem. Rev. 285, 11-23 (2015)

30. Vakili, R., Xu, S., Al-Janabi, N., Gorgojo, P., Holmes, S.M., Fan, X.: Microwave-assisted synthesis of zirconium-based metal organic frameworks (MOFs): optimization and gas adsorption. Microporous Mesoporous Mater. 260, 45-53 (2018)

31. McKinstry, C., Cussen, E.J., Fletcher, A.J., Patwardhan, S.V., Sefcik, J.: Scalable continuous production of high quality HKUST-1 via conventional and microwave heating. Chem. Eng. J. 326, 570-577 (2017)

32. Schlesinger, M., Schulze, S., Hietschold, M., Mehring, M.: Evaluation of synthetic methods for microporous metalorganic frameworks exemplified by the competitive formation of $\left[\mathrm{Cu}_{2}(\mathrm{btc})_{3}\left(\mathrm{H}_{2} \mathrm{O}\right)_{3}\right]$ and $\left[\mathrm{Cu}_{2}(\mathrm{btc})(\mathrm{OH})\left(\mathrm{H}_{2} \mathrm{O}\right)\right]$. Microporous Mesoporous Mater. 132, 121-127 (2010)

33. Masoomi, M.Y., Bagheri, M., Morsali, A.: High adsorption capacity of two Zn-based metal-organic frameworks by ultrasound assisted synthesis. Ultrason. Sonochem. 33, 54-60 (2016)

34. Li, Z., Qiu, L., Xu, T., Wu, Y., Wang, W., Wu, Z., Jiang, X.: Ultrasonic synthesis of the microporous metal-organic framework $\mathrm{Cu}_{3}(\mathrm{BTC})_{2}$ at ambient temperature and pressure: an efficient and environmentally friendly method. Mater. Lett. 63, 78-80 (2009)

35. Razavi, S.A.A., Masoomi, M.Y., Morsali, A.: Ultrasonic assisted synthesis of a tetrazine functionalized MOF and its application in colorimetric detection of phenylhydrazine. Ultrason. Sonochem. 37, 502-508 (2017)

36. Armstrong, M.R., Senthilnathan, S., Balzer, C.J., Shan, B., Chen, L., Mu, B.: Particle size studies to reveal crystallization mechanisms of the metal organic framework HKUST-1 during sonochemical synthesis. Ultrason. Sonochem. 34, 365-370 (2017)

37. Masoomi, M.Y., Bagheri, M., Morsali, A.: Porosity and dye adsorption enhancement by ultrasonic synthesized Cd(II) based 
metal-organic framework. Ultrason. Sonochem. 37, 244-250 (2017)

38. Lestari, W.W., Arvinawati, M., Martien, R., Kusumaningsih, T.: Green and facile synthesis of MOF and nano MOF containing zinc(II) and benzene 1,3,5-tri carboxylate and its study in ibuprofen slow-release. Mater. Chem. Phy. 204, 141-146 (2018)

39. Bosch, M., Zhang, M., Zhou, H.: Increasing the stability of metal-organic frameworks. Adv. Chem. (2014). https://doi. org/10.1155/2014/182327

40. Chevreau, H., Devic, T., Salles, F., Maurin, G., Stock, N., Serre, C.: Mixed-linker hybrid superpolyhedra for the production of a series of large-pore Iron(III) carboxylate metal-organic frameworks. Angew. Chem. 52, 5056-5060 (2013)

41. Devic, T., Serre, C.: High valence $3 p$ and transition metal based MOFs. Chem. Soc. Rev. 43, 6097-6115 (2014)

42. Mondloch, J.E.: Vapor-phase metalation by atomic layer deposition in a metal-organic framework. J. Am. Chem. Soc. 135, 10294-10297 (2013)

43. Fu, Y.H.: An amine-functionalized titanium metal-organic framework photocatalyst with visible-light-induced activity for $\mathrm{CO}_{2}$ reduction. Angew. Chem. Int. Ed. Engl. 51, 3364-3367 (2012)

44. ul Qadir, N., Said, S.A.M., Bahaidarah, H.M.: Structural stability of metal organic frameworks in aqueous media-controlling factors and methods to improve hydrostability and hydrothermal cyclic stability. Microporous Mesoporous. Mater. 201, 61-90 (2015)

45. Li, W., Thirumurugan, A., Barton, P.T., Lin, Z., Henke, S., Yeung, H.H.-M., Wharmby, M.T., Bithell, E.G., Howard, C.J., Cheetham, A.K.: Mechanical tunability via hydrogen bonding in metal-organic frameworks with the perovskite architecture. J. Am. Chem. Soc. 136, 7801-7804 (2014)

46. Yang, J., Grzech, A., Mulder, F.M., Dingemans, T.J.: Methyl modified MOF-5: a water stable hydrogen storage material. Chem. Commun. 47, 5244-5246 (2011)

47. Serre, C.: Superhydrophobicity in highly fluorinated porous metal-organic frameworks. Angew. Chem. Int. Ed. Engl. 51, 6048-6050 (2012)

48. Howarth, A.J., Liu, Y., Li, P., Li, Z., Wang, T.C., Huppand, J.T., Farha, O.K.: Chemical, thermal and mechanical stabilities of metal-organic framework. Nat. Rev. Mater. 1, 1-15 (2016)

49. Zhang, L., Su, C.: Applications of metal-organic frameworks in heterogeneous supramolecular catalysis. Chem. Soc. Rev. 43, 6011-6061 (2014)

50. Hu, M., Safarifar, V., Doustkhah, E.: Taking organic reactions over metal-organic frameworks as heterogeneous catalysis. Microporous Mesoporous Mater. 256, 111-127 (2018)

51. Zhu, C., Mao, Q., Li, D., Li, C., Zhou, Y., Wu, X., Luo, Y., Li, Y.: A readily available urea based MOF that act as a highly active heterogeneous catalyst for Friedel-Crafts reaction of indoles and nitrostryenes. Catal. Commun. 104, 123-127 (2018)

52. Calleja, G., Sanz, R., Orcajo, G., Briones, D., Leo, P., Martínez, F.: Copper-based MOF-74 material as effective acid catalyst in Friedel-Crafts acylation of anisole. Catal. Today 227, 130-137 (2014)

53. Anbu, N., Dhakshinamoorthy, $\mathrm{A} .: \mathrm{Cu}_{3}(\mathrm{BTC})_{2}$ as a viable heterogeneous solid catalyst for Friedel-Crafts alkylation of indoles with nitroalkenes. J. Colloid Interface Sci. 494, 282-289 (2017)

54. Phan, N.T.S., Le, K.K.A., Phan, T.D.: MOF-5 as an efficient heterogeneous catalyst for Friedel-Crafts alkylation reactions. Appl. Catal. A Gen. 382, 246-253 (2010)

55. Nguyen, L.T.L., Nguyen, C.V., Dang, G.H., Le, K.K.A., Phan, N.T.S.: Towards applications of metal-organic frameworks in catalysis: Friedel-Crafts acylation reaction over IRMOF-8 as an efficient heterogeneous catalyst. J. Mol. Catal. A Chem. 349, 28-35 (2011)
56. Gascon, J., Aktay, U., Hernandez-Alonso, M.D., van Klink, G.P.M., Kapteijn, F.: Amino-based metal-organic frameworks as stable, highly active basic catalysts. J. Catal. 261, 75-87 (2009)

57. Hartmann, M., Fischer, M.: Amino-functionalized basic catalysts with MIL-101 structure. Microporous Mesoporous Mater. 164, 38-43 (2012)

58. Yang, Y., Yao, H., Xi, F., Gao, E.: Amino-functionalized Zr(IV) metal-organic framework as bifunctional acid-base catalyst for Knoevenagel condensation. J. Mol. Catal. A Chem. 390, 198-205 (2014)

59. Llabrés i Xamena, F.X., Cirujano, F.G., Corma, A.: An unexpected bifunctional acid base catalysis in IRMOF-3 for Knoevenagel condensation reactions. Microporous Mesoporous Mater. 157, 112-117 (2012)

60. Martínez, F., Orcajo, G., Briones, D., Leo, P., Calleja, G.: Catalytic advantages of $\mathrm{NH}_{2}$-modified MIL-53(Al) materials for Knoevenagel condensation reaction. Microporous Mesoporous Mater. 246, 43-50 (2017)

61. Saha, D., Maity, T., Sen, R., Koner, S.: Heterogeneous catalysis over a barium carboxylate framework compound: synthesis, $\mathrm{X}$-ray crystal structure and aldol condensation reaction. Polyhedron 43, 63-70 (2012)

62. Pathan, N.B., Rahatgaonkar, A.M., Chorghade, M.S.: Metalorganic framework $\mathrm{Cu}_{3}(\mathrm{BTC})_{2}\left(\mathrm{H}_{2} \mathrm{O}\right)_{3}$ catalyzed Aldol synthesis of pyrimidine-chalcone hybrids. Catal. Commun. 12, 1170-1176 (2011)

63. Kikhtyanin, O., Kubicka, D., Cejk, J.: Toward understanding of the role of Lewis acidity in aldol condensation of acetone and furfural using MOF and zeolite catalysts. Catal. Today 243, 158-162 (2015)

64. Anbu, N., Dhakshinamoorthy, A.: $\mathrm{Cu}_{3}(\mathrm{BTC})_{2}$ catalyzed oxidation of silane to silanol using TBHP or water as oxidants. Appl. Catal. A Gen. 544, 145-153 (2017)

65. Kholdeeva, O.A., Skobelev, I.Y., Ivanchikova, I.D., Kovalenkob, K.A., Fedin, V.P., Sorokin, A.R.B.: Hydrocarbon oxidation over $\mathrm{Fe}$ - and $\mathrm{Cr}$-containing metal-organic frameworks MIL-100 and MIL-101-a comparative study. Catal. Today 238, 54-61 (2014)

66. Skobelev, I.Y., Sorokin, A.B., Kovalenko, K.A., Fedin, V.P., Kholdeeva, O.A.: Solvent-free allylic oxidation of alkenes with $\mathrm{O}_{2}$ mediated by Fe- and Cr-MIL-101. J. Catal. 298, 61-69 (2013)

67. Torbina, V.V., Ivanchikova, I.D., Kholdeeva, O.A., Skobelev, I.Y., Vodyankina, O.V.: Propylene glycol oxidation with tertbutyl hydroperoxide over Cr-containing metal-organic frameworks MIL-101 and MIL-100. Catal Today 278, 97-103 (2016)

68. Phan, N.T.S., Nguyen, T.T., Nguyen, C.V., Nguyen, T.T.: Ullmann-type coupling reaction using metal-organic framework MOF-199 as an efficient recyclable solid catalyst. Appl. Catal. A Gen. 457, 69-77 (2013)

69. Chen, L., Gao, Z., Li, Y.: Immobilization of Pd(II) on MOFs as a highly active heterogeneous catalyst for Suzuki-Miyaura and Ullmann-type coupling reactions. Catal. Today $\mathbf{2 4 5}, \mathbf{1 2 2 - 1 2 8}$ (2015)

70. Nguyen, K.D., Doan, S.H., Ngo, A.N.V., Nguyen, T.T., Phan, N.T.S.: Direct $\mathrm{C}-\mathrm{N}$ coupling of azoles with ethers via oxidative $\mathrm{C}-\mathrm{H}$ activation under metal-organic framework catalysis. J. Ind. Eng. Chem. 44, 136-145 (2016)

71. Anbu, N., Dhakshinamoorthy, A.: $\mathrm{Cu}_{3}(\mathrm{BTC})_{2}$ catalyzed dehydrogenative coupling of dimethylphenylsilane with phenol and homocoupling of dimethylphenylsilane to disiloxane. J. Colloid Interface Sci. 490, 430-435 (2017)

72. Brown, J.W., Jarenwattananon, N.N., Otto, T., Wang, J.L., Glöggler, S., Bouchard, L.S.: Heterogeneous heck coupling in multivariate metal-organic frameworks for enhanced selectivity. Catal. Commun. 65, 105-107 (2015) 
73. Luz, F.X., Xamena, L., Corma, A.: Bridging homogeneous and heterogeneous catalysis with MOFs: $\mathrm{Cu}-\mathrm{MOFs}$ as solid catalysts for three-component coupling and cyclization reactions for the synthesis of propargylamines, indoles and imidazopyridines. J. Catal. 285, 285-291 (2012)

74. Dang, G.H., Lam, H.Q., Nguyen, A.T., Le, D.T., Truong, T., Phan, N.T.S.: Synthesis of indolizines through aldehyde-aminealkyne couplings using metal-organic framework $\mathrm{Cu}-\mathrm{MOF}-74$ as an efficient heterogeneous catalyst. J. Catal. 337, 167-176 (2016)

75. Zhang, L., Su, Z., Jiang, F., Zhou, Y., Xu, W., Hong, M.: Catalytic palladium nanoparticles supported on nanoscale MOFs: a highly active catalyst for Suzuki-Miyaura cross-coupling reaction. Tetrahedron 69, 9237-9244 (2013)

76. Neogi, S., Sharma, M.K., Bharadwaj, P.K.: Knoevenagel condensation and cyanosilylation reactions catalyzed by a MOF containing coordinatively unsaturated $\mathrm{Zn}$ (II) centers. J. Mol. Catal. A Chem. 299, 1-4 (2009)

77. Bhunia, A., Dey, S., Moreno, J.M., Diaz, U., Concepcion, P., Van Hecke, K., Janiak, C., Van Der Voort, P.: A homochiral vanadium-salen based cadmium bpdc MOF with permanent porosity as an asymmetric catalyst in solvent-free cyanosilylation. Chem. Commun. 52, 1401-1404 (2016)

78. Babu, R., Roshan, R., Gim, Y., Jang, Y.H., Kurisingal, J.F., Kim, D.W., Park, D.: Inverse relationship of dimensionality and catalytic activity in $\mathrm{CO}_{2}$ transformation: a systematic investigation by comparing multidimensional metal-organic frameworks. J. Mater. Chem. A 5, 15961-15969 (2017)

79. Babu, R., Roshan, R., Kathalikkattil, A.C., Kim, D.W., Park, D.-W.: Rapid, microwave-assisted synthesis of cubic, threedimensional, highly porous MOF-205 for room temperature $\mathrm{CO}_{2}$ fixation via cyclic carbonate synthesis. ACS Appl. Mater. Interfaces. 8, 33723-33731 (2016)

80. Kurian, M., Sugunan, S.: Tertiary butylation of phenol over iron pillared montmorillonites. Catal. Commun. 7, 417-421 (2006)

81. Kurian, M., Sugunan, S.: Selective benzylation of benzene over alumina pillared clays. Indian J. Chem. 56A, 1772-1781 (2005)

82. Kurian, M., Sugunan, S.: Selective benzylation of o-xylene over transition metal doped montmorillonites. React. Kinet. Catal. Lett. 81, 57 (2004)

83. Kurian, M., Sugunan, S.: Liquid phase benzylation of o-xylene over pillared clays. Indian J. Chem. 42A, 2480 (2003)

84. Nguyen, H.T.D., Nguyen, T.T., Nguyen, P.T.K., Horan, P.: A highly active copper-based metal-organic framework catalyst for a Friedel-Crafts alkylation in the under ultrasound irradiation. Arab. J. Chem. (2017). https://doi.org/10.1016/j.arabj c.2017.11.009

85. Ullah, L., Zhao, G., Xu, Z., He, H., Usman, M., Zhang, S.: 12-Tungstophosphoric acid niched in $\mathrm{Zr}$-based metal-organic framework: a stable and efficient catalyst for Friedel-Crafts acylation. Sci. China Chem. 61(4), 402-411 (2018)

86. Rao, P.C., Mandal, S.: Friedel-Crafts alkylation of indoles with ntroalkenes through hydrogen-bond-donating metal-organic framework. ChemCatChem 9(7), 1172-1176 (2017)

87. Rahmani, E., Rahmani, M.: Al-Based MIL-53 metal organic framework (MOF) as the new catalyst for Friedel-Crafts alkylation of benzene. Ind. Eng. Chem. Res. 57(1), 169-178 (2018)

88. Jiang, J.Y.S., Ji, S., Shi, D., Cheng, H.: Metal-organic framework MIL-53(Al): synthesis, catalytic performance for the FriedelCrafts acylation, and reaction mechanism. Sci. China Chem. 58(10), 1544-1552 (2015)

89. Calleja, G., Sanz, R., Orcajo, G., Briones, D., Leo, P., Martínez, F.: Copper-based MOF-74 material as effective acid catalyst in Friedel-Crafts acylation of anisole. Catal. Today 21(227), 130137 (2014)
90. Doan, T.L.H., Dao, T.Q., Tran, H.N., Tran, P.H., Thach, N.L.: Friedel-Crafts benzoylation of arenes: an efficient combination of $\mathrm{Zr}-\mathrm{MOF}$ and microwave irradiation in catalytic Lewis acid Friedel-Crafts benzoylation. Dalton Trans. 45(18), 7875-7880 (2016)

91. Jiang, S., Yan, J., Habimana, F., Ji, S.: Preparation of magnetically recyclable MIL-53(Al)@ $\mathrm{SiO}_{2} @ \mathrm{Fe}_{3} \mathrm{O}_{4}$ catalysts and their catalytic performance for Friedel-Crafts acylation reaction. Catal. Today 264, 83-90 (2016)

92. Farzaneh, F., Mortazavi, S.S.: Zn metal organic framework as a heterogeneous catalyst for the alkylation of toluene with benzyl bromide. React. Kinet. Mech. Catal. 120(1), 333-344 (2017)

93. Khalil, T., Mohammad, A.Z., Nosrat, O.M., Tooraj, E.: Introduction of an effective and economical heterogeneous ruthenium catalyst for regioselective ring-opening of epoxides and the Friedel-Crafts alkylation reaction of indoles and pyrroles. Lett. Org. Chem. 14(3), 207-217 (2017)

94. Chung, Y., Kim, H., Ahn, W.: Friedel-Crafts acylation of $p$-xylene over sulfonated zirconium terephthalates. Catal. Lett. 144, 817-824 (2014)

95. Zhu, N., Zhao, C., Wang, J., Li, Y., Dong, Y.: Micro-Cu $\mathrm{Cu}_{4} \mathrm{I}_{4}-\mathrm{MOF}$ : reversible iodine adsorption and catalytic properties for tandem reaction of Friedel-Crafts alkylation of indoles with acetals. Chem. Commun. 52, 12702 (2016)

96. Rostamnia, S., Alamgholiloo, H., Liu, X.: Pd-grafted open metal site copper-benzene-1,4-dicarboxylate metal organic frameworks (Cu-BDC MOF's) as promising interfacial catalysts for sustainable Suzuki coupling. J. Colloid Interface Sci. 469, 310-317 (2016)

97. Zhang, W., Li, Q., Zhang, Q., Lu, Y., Lu, H., Wang, W., Zhao, X., Wang, X.: Robust metal-organic framework containing benzoselenadiazole for highly efficient aerobic cross-dehydrogenative coupling reactions under visible light. Inorg. Chem. 55(3), 1005-1007 (2016)

98. Chen, Y., Jiang, H.: Porphyrinic metal-organic framework catalyzed heck-reaction: fluorescence "turn-on" sensing of $\mathrm{Cu}(\mathrm{II})$ ion. Chem. Mater. 28(18), 6698-6704 (2016)

99. Kardanpour, R., Tangestaninejad, S., Mirkhani, V., Moghadam, M., Baltork, I.M., Khosropour, A.R., Zadehahmadi, F.: Highly dispersed palladium nanoparticles supported on amino functionalized metal-organic frameworks as an efficient and reusable catalyst for Suzuki cross-coupling reaction. J. Organomet. Chem. 761, 127-133 (2014)

100. Rostamnia, S., Morsali, A.: Basic isoreticular nanoporous metal-organic framework for Biginelli and Hantzsch coupling: IRMOF-3 as a green and recoverable heterogeneous catalyst in solvent-free conditions. RSC Adv. 4, 54487-54493 (2014)

101. Zhang, L., Feng, C., Gao, S., Wang, Z., Wang, C.: Palladium nanoparticle supported on metal-organic framework derived $\mathrm{N}$-decorated nanoporous carbon as an efficient catalyst for the Suzuki coupling reaction. Catal. Commun. 61, 21-25 (2015)

102. Qiu, X., Len, C., Luque, R., Li, Y.: Solventless oxidative coupling of amines to imines by using transition-metal-free metalorganic frameworks. ChemSusChem 7(6), 1684-1688 (2014)

103. Wang, B., Yang, P., Ge, Z., Li, C.: A porous metal-organic framework as active catalyst for multiple $\mathrm{C}-\mathrm{N} / \mathrm{C}-\mathrm{C}$ bond formation reactions. Inorg. Chem. Commun. 61, 13-15 (2015)

104. Yang, X., Zou, C., Yabing He, M., Zhao, B., Chen, S., Xiang, M., O'Keeffe, CWu: A stable microporous mixed-metal metalorganic framework with highly active $\mathrm{Cu}^{2+}$ sites for efficient cross-dehydrogenative coupling reactions. Chem. A Eur. J. 20(5), 1447-1452 (2014)

105. Horike, S., Dinca , M., Tamaki, K., Long, J.R.: Size-selective lewis acid catalysis in a microporous metal-organic framework with exposed $\mathrm{Mn}^{2+}$ coordination sites. J. Am. Chem. Soc. 130, 5854-5855 (2008) 
106. Schlichte, K., Kratzke, T., Kaskel, S.: Improved synthesis, thermal stability and catalytic properties of the metal-organic framework compound $\mathrm{Cu}_{3}(\mathrm{BTC})_{2}$. Microporous Mesoporous Mater. 73(1-2), 81-88 (2004)

107. Gao, W., Chen, Y., Niu, Y., Williams, K., Cash, L., Perez, P.J., Wojtas, L., Cai, J., Chen, Y., Ma, S.: Crystal engineering of an nbo topology metal-organic framework for chemical fixation of $\mathrm{CO}_{2}$ under ambient conditions. Angew. Chem. Int. Ed. 53, 2615-2619 (2014)

108. Li, P., Wang, X., Liu, J., Lim, J.S., Zou, R., Zhao, Y.: A triazolecontaining metal-organic framework as a highly effective and substrate size-dependent catalyst for $\mathrm{CO}_{2}$ conversion. J. Am. Chem. Soc. 138(7), 2142-2145 (2016)

109. De, D., Pal, T.K., Neogi, S., Senthilkumar, S., Das, D., Gupta, S.S., Bharadwaj, P.K.: A versatile CuII metal-organic framework exhibiting high gas storage capacity with selectivity for $\mathrm{CO}_{2}$ : conversion of $\mathrm{CO}_{2}$ to cyclic carbonate and other catalytic abilities. Chem. A Eur. J. 22(10), 3387-3396 (2016)

110. Cho, S., Ma, B., Nguyen, S.T., Hupp, J.T., Albrecht-Schmitt, T.E.: A metal-organic framework material that functions as an enantioselective catalyst for olefin epoxidation. Chem. Commun. 24, 2563-2565 (2006)

111. Alaerts, L., Séguin, E., Poelman, H., Thibault-Starzyk, F., Jacobs, P.A., De Vos, D.E.: Probing the lewis acidity and catalytic activity of the metal-organic framework $\left[\mathrm{Cu}_{3}(\mathrm{btc})_{2}\right](\mathrm{BTC}=$ Benzene-1,3,5-tricarboxylate). Chem. A Eur. J. 12(28), 7271-7531 (2006)

112. Sun, C., Liu, S., Liang, D., Shao, K., Ren, Y., Su, Z.: Highly stable crystalline catalysts based on a microporous metal-organic framework and polyoxometalates. J. Am. Chem. Soc. 131(5), 1883-1888 (2009)

113. Wu, C., Hu, A., Zhang, L., Lin, W.: A homochiral porous metalorganic framework for highly enantioselective heterogeneous asymmetric catalysis. J. Am. Chem. Soc. 127(25), 8940-8941 (2005)

114. Vermoortele, F., Ameloot, R., Vimont, A., Serrec, C., De Vos, D.: An amino-modified $\mathrm{Zr}$-terephthalate metal-organic framework as an acid-base catalyst for cross-aldol condensation. Chem. Commun. 47(5), 1521-1523 (2011)

115. Feng, D., Gu, Z., Li, J., Jiang, H., Wei, Z., Zhou, H.: Mesoporous metal-organic frameworks with ultrahigh stability as biomimetic catalysts. Angew. Chem. Int. Ed. 51, 10307-10310 (2012)

116. Pérez-Mayoral, E., Čejka, J.: $\left[\mathrm{Cu}_{3}(\mathrm{BTC})_{2}\right]$ : a metal-organic framework catalyst for the friedländer reaction. ChemCatChem 3(1), 157-159 (2011)

117. Song, J., Luo, Z., Britt, D.K., Furukawa, H., Yaghi, O.M., Hardcastle, K.I., Hill, C.L.: $\left[\mathrm{Cu}_{3}\left(\mathrm{C}_{9} \mathrm{H}_{3} \mathrm{O}_{6}\right)_{2}\right]_{4}$ $\left[\left\{\left(\mathrm{CH}_{3}\right) 4 \mathrm{~N}\right\} 4 \mathrm{CuPW}_{11} \mathrm{O}_{39} \mathrm{H}\right]$ a multiunit catalyst with synergistic stability and reactivity: a polyoxometalate metal organic framework for aerobic decontamination. J. Am. Chem. Soc. 133, 16839-16846 (2011)

118. Comito, R.J., Fritzsching, K.J., Sundell, B.J., Schmidt-Rohr, K., Dinca, M.: $\mathrm{Zn}_{5} \mathrm{Cl}_{4}(\mathrm{BTDD})_{3}$-single-site heterogeneous catalysts for olefin polymerization enabled by cation exchange in a metalorganic framework. J. Am. Chem. Soc. 138, 10232-10237 (2016)

119. Manna, K., Zhang, T., Carboni, M., Abney, C.W., Lin, W.: Feand Co-functionalized MOFs (sal-M-MOF, $\mathrm{M}=\mathrm{Fe}$, Co)-salicylaldimine-based metal-organic framework enabling highly active olefin hydrogenation with iron and cobalt catalysts. J. Am. Chem. Soc. 136, 13182-13185 (2014)

120. Lin, S., Diercks, C.S., Zhang, Y., Kornienko, N., Nichols, E.M., Zhao, Y., Paris, A.R., Kim, D., Yang, P., Yaghi, O.M., Chang, C.J.: Covalent organic frameworks comprising cobalt porphyrins for catalytic $\mathrm{CO}_{2}$ reduction in water. Science 349(6253), 1208-1213 (2015)
121. Liu, Y., Howarth, A.J., Hupp, J.T., Farha, O.K.: Selective photooxidation of a mustard-gas simulant catalyzed by a porphyrinic metal-organic framework. Angew. Chem. Int. Ed. 54(31), 9001-9005 (2015). https://doi.org/10.1002/anie.201503741

122. Liu, Y., Moon, S.Y., Hupp, J.T., Farha, O.K.: Dual-function metal-organic framework as a versatile catalyst for detoxifying chemical warfare agent simulants. ACS Nano 9(12), 1235812364 (2015)

123. López-Maya, E., Montoro, C., Rodríguez-Albelo, L.M., Aznar Cervantes, S.D., Cenís, J.L.: Textile/metal-organic-framework composites as self-detoxifying filters for chemical-warfare agents. Angew. Chem. Int. Ed. 54(23), 6790-6794 (2015)

124. Hod, I., Deria, P., Bury, W., Mondloch, J.E., Kung, C., So, M., Sampson, M.D., Peters, A.W., Kubiak, C.P., Farha, O.K., Hup, J.T.: A porous proton-relaying metal-organic framework material that accelerates electrochemical hydrogen evolution. Nat. Commun. 6, 8304 (2015)

125. Reinares-Fisac, D., Aguirre-Díaz, L.M., Iglesias, M., Snejko, N., Gutiérrez-Puebla, E., Monge, M.Á., Gándara, F.: A mesoporous indium metal-organic framework: remarkable advances in catalytic activity for strecker reaction of ketones. J. Am. Chem. Soc. 138(29), 9089-9092 (2016)

126. Gonzalez, M.I., Bloch, E.D., Mason, J.A., Teat, S.J., Long, J.R.: Single-crystal-to-single-crystal metalation of a metal-organic framework: a route toward structurally well-defined catalysts. Inorg. Chem. 54, 2995-3005 (2015)

127. Klet, R.C., Tussupbayev, S., Borycz, J., Gallagher, J.R., Stalzer, M.M., Miller, J.T., Gagliardi, L., Hupp, J.T., Marks, T.J., Cramer, C.J., Delferro, M., Farha, O.K.: Single-site organozirconium catalyst embedded in a metal-organic framework. J. Am. Chem. Soc. 137(50), 15680-15683 (2015)

128. Beyzavi, M.H., Vermeulen, N.A., Howarth, A.J., Tussupbayev, S., League, A.B., Schweitzer, N.M., Farha, O.K.: A hafniumbased metal-organic framework as a nature-inspired tandem reaction catalyst. J. Am. Chem. Soc. 137(42), 13624-13631 (2015). https://doi.org/10.1021/jacs.5b08440

129. Nasalevich, M.A., Becker, R., Ramos-Fernandez, E.V., Castellanos, S., Veber, S.L., Fedin, M.V., Kapteijn, F., Reek, J.N.H., van der Vlugt, J.I., Gascon, J.: Co@ $\mathrm{NH}_{2}-\mathrm{MIL}-125$ (Ti): cobaloxime-derived metal- organic framework-based composite for light driven $\mathrm{H}_{2}$ production. Energy Environ. Sci. 55, 9 (2014). https:// doi.org/10.1039/c4ee02853h

130. Jiao, L., Zhou, Y., Jiang, H.: Metal-organic framework-based $\mathrm{CoP} /$ reduced graphene oxide: high-performance bifunctional electrocatalyst for overall water splitting. Chem. Sci. 7, 16901695 (2016)

131. Zhao, M., Deng, K., He, L., Liu, Y., Li, G., Zhao, H., Tang, Z.: Core-shell palladium nanoparticle@metal-organic frameworks as multifunctional catalysts for cascade reactions. J. Am. Chem. Soc. 136(5), 1738-1741 (2014)

132. Chen, Y., Xu, Q., Yu, S., Jiang, H.: Tiny Pd@Co core-shell nanoparticles confined inside a metal-organic framework for highly efficient catalysis. Small 11(1), 71-76 (2015)

133. Qi, Y., Luan, Y., Yu, J., Peng, X., Wang, G.: Nanoscaled copper metal-organic framework (MOF) based on carboxylate ligands as an efficient heterogeneous catalyst for aerobic epoxidation of olefins and oxidation of benzylic and allylic alcohols. Chem. A Eur. J. 21(4), 1589-1597 (2015)

134. Noh, H., Cui, Y., Peters, A.W., Pahls, D.R., Ortuño, M.A., Vermeulen, N.A., Cramer, C.J., Gagliardi, L., Hupp, J.T., Farha, O.K.: An exceptionally stable metal-organic framework supported molybdenum(VI) oxide catalyst for cyclohexene epoxidation. J. Am. Chem. Soc. 138(44), 14720-14726 (2016) 
135. Mo, K., Yang, Y., Cui, Y.: Li MOF-a homochiral metal-organic framework as an effective asymmetric catalyst for cyanohydrin synthesis. J. Am. Chem. Soc. 136(5), 1746-1749 (2014)

136. Manna, K., Ji, P., Greene, F.X., Lin, W.: Metal-organic framework nodes support single-site magnesium-alkyl catalysts for hydroboration and hydroamination reactions. J. Am. Chem. Soc. 138(24), 7488-7749 (2016)

137. Hu, H., Han, L., Yu, M., Wang, Z., Lou, X.: Metal-organicframework-engaged formation of Co nanoparticle-embedded carbon@ $\mathrm{Co}_{9} \mathrm{~S}_{8}$ double-shelled nanocages for efficient oxygen reduction. Energy Environ. Sci. 9, 107-111 (2016)

138. Xia, B.Y., Yan, Y., Li, N., Wu, H.B., Lou, X.W., Wang, X.: A metal-organic framework-derived bifunctional oxygen electrocatalyst. Nat. Energy 1, 15006 (2016)

139. Li, Z., Schweitzer, N.M., League, A.B., Bernales, V., Peters, A.W., Getsoian, A.B., Farha, O.K.: Sintering-resistant singlesite nickel catalyst supported by metal-organic framework. J. Am. Chem. Soc. 138(6), 1977-1982 (2016). https://doi.org/10.1021/ jacs.5b12515

140. Hod, I., Sampson, M.D., Deria, P., Kubiak, C.P., Farha, O.K., Hupp, J.T.: Fe-porphyrin-based metal-organic framework films as high-surface concentration, heterogeneous catalysts for electrochemical reduction of $\mathrm{CO}_{2}$. ACS Catal. 5(11), 6302-6309 (2015)

141. Yang, Q., Xu, Q., Yu, S., Jiang, H.: Pd nanocubes@ZIF-8: integration of plasmon-driven photothermal conversion with a metalorganic framework for efficient and selective catalysis. Angew. Chem. Int. Ed. 55(11), 3685-3689 (2016)
142. Beyzavi, M.H., Klet, R.C., Tussupbayev, S., Borycz, J., Vermeulen, N.A., Cramer, C.J., Farha, O.K.: A hafnium-based metalorganic framework as an efficient and multifunctional catalyst for facile $\mathrm{CO}_{2}$ fixation and regioselective and enantioretentive epoxide activation. J. Am. Chem. Soc. 136(45), 15861-15864 (2014). https://doi.org/10.1021/ja508626n

143. Li, B., Leng, K., Zhang, Y., Dynes, J.J., Wang, J., Hu, Y., Ma, D., Shi, Z., Zhu, L., Zhang, D., Sun, Y., Chrzanowski, M., Ma, S.: MIL-101-Cr-SO ${ }_{3} \mathrm{H} \cdot \mathrm{Al}$ (III) MOF-metal-organic framework based upon the synergy of a brønsted acid framework and lewis acid centers as a highly efficient heterogeneous catalyst for fixed-bed reactions. J. Am. Chem. Soc. 137, 4243-4248 (2015)

144. Fei, H., Sampson, M.D., Lee, Y., Kubiak, C.P., Cohen, S.M.: Photocatalytic $\mathrm{CO}_{2}$ reduction to formate using a $\mathrm{Mn}(\mathrm{I})$ molecular catalyst in a robust metal-organic framework. Inorg. Chem. 54(14), 6821-6828 (2015)

145. Sawano, T., Thacker, N.C., Lin, Z., McIsaac, A.R., LinRobust, W.: Chiral, and porous BINAP-based metal-organic frameworks for highly enantioselective cyclization reactions. J. Am. Chem. Soc. 137(38), 12241-12248 (2015)

Publisher's Note Springer Nature remains neutral with regard to jurisdictional claims in published maps and institutional affiliations. 